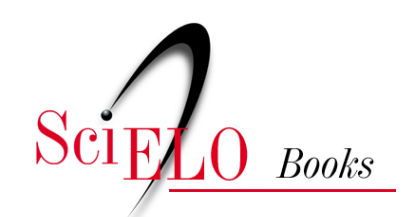

Editora da UESC

\title{
Dialogismo entre textos bíblicos e poemas de Valdo Motta na construção do tema homoerótico
}

\author{
Carlos Eduardo Albuquerque Fernandes
}

\section{SciELO Books / SciELO Livros / SciELO Libros}

FERNANDES, CEA. Dialogismo entre textos bíblicos e poemas de Valdo Motta na construção do tema homoerótico. In: MITIDIERI, AL., and CAMARGO, FP., orgs. Literatura, homoerotismo e expressões homoculturais [online]. Ilhéus, BA: Editus, 2015, pp. 77-96. ISBN 978-85-7455-442-6. Available from SciELO Books $<$ http://books.scielo.org $>$.

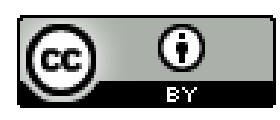

All the contents of this work, except where otherwise noted, is licensed under a Creative Commons Attribution $\underline{4.0 \text { International license. }}$

Todo o conteúdo deste trabalho, exceto quando houver ressalva, é publicado sob a licença Creative Commons Atribição 4.0.

Todo el contenido de esta obra, excepto donde se indique lo contrario, está bajo licencia de la licencia Creative Commons Reconocimento 4.0. 


\section{DIALOGISMO ENTRE TEXTOS BÍBLICOS E POEMAS DE VALDO MOTTA NA CONSTRUÇÃO DO TEMA HOMOERÓTICO}

Carlos Eduardo Albuquerque Fernandes ${ }^{1}$

\section{Questões introdutórias}

A relação entre o homoerotismo e as práticas discursivas sobre o "sagrado" na religião cristã quase sempre foi pontos de conflito, haja vista o caráter pecaminoso que era (é), do ponto de vista bíblico, um homem que se deita com outro homem como se fosse mulher, conforme lemos nas leis mosaicas expressas no livro de Levítico 20:13: "Se também um homem se deitar com outro homem, como se fosse mulher, ambos praticaram coisa abominável; serão mortos; o seu sangue cairá sobre eles".

Graças à tradição exegética, os sujeitos que praticaram "coisa abominável" foram silenciados ao longo da história e, consequentemente, a recepção da temática homoafetiva no texto literário também causou muitos conflitos. Quando Bom Crioulo - romance brasileiro a abordar o amor entre dois homens, em 1895 -,

1 Professor da Universidade Federal Rural de Pernambuco; doutorando em Letras pela Universidade Federal da Paraíba. E-mail: <eduardo-af-@hotmail.com>. 
de Adolfo Caminha, foi recebido pela sociedade, causando escândalo e, ainda que permeado pelos julgamentos decadentistas do naturalismo, a relação entre Amaro e Aleixo provocou os críticos e atrapalhou a recepção do livro. No mesmo ano da publicação de Bom Crioulo, Oscar Wilde, famoso dramaturgo inglês, autor do romance de temática gay, $O$ retrato de Dorian Gray, foi condenado a dois anos de prisão com trabalhos forçados sob a acusação de praticar sodomia (FRY; MACRAE, 1983).

O termo "sodomia", que possui origem na tradição bíblica, nos remete à narrativa sobre a cidade de Sodoma, para onde o personagem Ló se dirigiu ao separar-se do tio Abrão. O narrador do Gênesis afirma que os habitantes de Sodoma "eram maus e grandes pecadores contra o Senhor" (Gênesis 13:13) e por causa de seus pecados, a cidade foi destruída (Gênesis 19), demonstrando a insatisfação divina com as ações dos sodomitas, que eram as práticas sexuais não destinadas à procriação (o coito anal, o coito com animais), e dentre elas, práticas sexuais entre homens de maneira condenável.

Assim, também, a literatura que aborda a temática homoerótica tem assumido o posto delegado pelo discurso teológico sobre as relações afetivo-sexuais entre pessoas do mesmo sexo; tendo sido rotulada de literatura maldita, tornou-se pouco lida, estudada e publicada, haja vista as barreiras canônicas e exegéticas em se permitir um diálogo aberto sobre esse tema. 
Um episódio importante envolvendo literatura, homoerotismo e religião, ocorreu em 1923, quando os escritores portugueses António Botto e Raul Leal escreveram obras que tornavam visivel o desejo sexual entre pessoas do mesmo sexo em personagens e sujeitos poéticos; a atitude dos escritores foi nomeada de "literatura de Sodoma", e um grupo de estudantes de cunho católico reagiu contra as publicações:

Daí em diante, seguem-se notícias de perseguição e censura aos livreiros, culminando com uma ação violenta dos estudantes sobre livrarias que expunham e vendiam obras de Botto e de Leal e com a proibição por parte do governo civil de Lisboa da exposição e venda de tais obras em março de 1923, instalando uma censura oficial que não era praticada desde os tempos da Revolução Constitucionalista de 1820 (LUGARINHO, 2003, p.139).

O motivo religioso, nesse episódio da história de Portugal, foi o agravante para o rechaço da literatura de temática homoerótica, bem como o de seus escritores. A religião sempre exerceu forte influência na cultura das sociedades ocidentais em suas práticas discursivas e sexuais, como nos confirmam Magalhães e Silva (2008, p.160-161):

A religião encontrou distintas formas de lidar com os corpos, de interpretá -los e incluí-los em sua vasta simbo- 
logia. Não é conhecida uma religião, no mundo, que não tenha construído uma ética do corpo e da sexualidade. [...] A vigilância e o controle dos corpos, a divisão radical entre papéis do homem e da mulher são expressões destas relações, não as únicas.

Em contraponto a essa tradição de controle dos corpos, as questões de gênero e de sexualidade voltadas para as minorias culturais vêm ocupando um espaço de discussão cada vez maior e relevante nas sociedades ocidentais. Devido às transformações culturais pelas quais passam as sociedades na modernidade tardia ou na pós-modernidade (nomenclaturas utilizadas por Hall, 1997), fragmentam-se as paisagens culturais de classe, gênero, sexualidade, etnia, dentre outras categorias que, em meio à globalização, através do encontro e de mistura entre as culturas, e das rupturas do conhecimento moderno, caracterizam o contexto cultural em que novas maneiras de perceber as diferenças se apresentam viáveis e necessárias.

Nossa discussão se centra, portanto, na abordagem de dois temas que parecem trilhar caminhos opostos nas práticas discursivas: religião e homoerotismo, uma vez que a primeira insiste em "controlar os corpos", como afirmam Magalhães e Silva (2008); e o segundo encena-se numa atividade de construção e desconstrução de normas, "como transgressão social, demolição das barreiras entre classes, portanto libertação do indivíduo" (FERNANDEZ citado por BARCELLOS, 2006, p. 135). 
Chama-nos atenção, no entanto, o fato de a literatura aproximar os dois temas, estruturando-se o desejo homoerótico expresso por sujeitos poéticos e por personagens de ficção através do diálogo com imagens, personagens e símbolos de textos bíblicos, considerados sagrados pelo discurso teológico, o que nos incita a perguntar: que implicação pode haver na representação do homoerotismo através do dialogismo com o texto bíblico? Diante dessa questão, nosso objetivo é investigar as relações dialógicas entre a literatura de temática homoerótica e textos bíblicos, buscando analisar em que medida essas relações contribuem para uma perspectiva de maior abertura às relações homoafetivas do ponto de vista cultural. Tomamos como corpus de análise o livro de poemas Bundo e outros poemas (1996), de Valdo Motta, para assim tentar discutir a presença do discurso considerado sagrado na literatura de temática homoerótica².

É importante destacarmos algumas noções importantes a respeito das bases teóricocriticas sobre as quais pretendemos discutir os textos literários em questão. Partimos do princípio bakhtiniano de que, do ponto de vista do funcionamento da linguagem, "todos os

2 Empregamos a expressão Literatura de temática homoerótica a partir de Silva (2007) e Lugarinho (2008), que a usam para se referir às obras literárias que centralizam o tema das relações entre pessoas do mesmo sexo. Podemos citar algumas obras literárias de temática homoerótica que dialogam com textos bíblicos: o conto homônimo de Testamento de Jônatas deixado a David (1976), de João Silvério Trevisan; alguns poemas de Ciclones (1997), de Roberto Piva; e alguns contos de Eis o mistério da Fé (2009), de Antonio de Pádua Dias da Silva. 
enunciados constituem-se através de outros" (FIORIN, 2006, p. 30). E, portanto, as relações dialógicas nos textos literários são recorrentes entre diversos temas e textos formando uma rede através da qual podemos ver, por meio de uma leitura atenta, os entrelaçamentos textuais e ideológicos.

Assim, entendemos que a literatura de temática homoerótica pode estabelecer relação dialógica com textos, discursos bíblicos/ sagrados. Preferimos adotar a denominação bakhtiniana de dialogismo por esta parecer mais abrangente do que a intertextualidade e interdiscursividade (haja vista também a especificidade que cada uma dessas categorias possui para diferentes autores), uma vez que diz respeito desde a própria constituição do ser humano (MORSON; EMERSON, 2008) até as relações de elementos estruturais e alusões ideológicas que podem haver nos textos.

Para além das nossas impressões sobre as relações dialógicas entre o sagrado e a literatura, concordamos com Eliade (1989, citado por SILVA, 2004, p. 55) quando afirma que a experiência com o sagrado

[...] faz parte de um conjunto de experiências humanas mais profundas que, antes de serem trazidas à linguagem verbal, ficam codificadas no interior do ser humano formando uma complexa rede, uma espécie de fundo simbólico.

E, assim, a literatura, independente do gênero literário ou tema no qual se centra, 
parece estar tomada desse "fundo simbólico", lançando mão de metáforas, alusões, ou mesmo através da transcrição de textos considerados sagrados, dependendo da cultura. Resta, então, discutir os poemas escolhidos e argumentar sobre esse curioso dialogismo entre a poética de Valdo Motta e a Bíblia.

\section{"O vosso corpo é santuário do Espírito Santo" (I Corintios 6: 19)}

A obra Bundo e outros poemas (1996), do escritor capixaba Valdo Motta ${ }^{3}$, é marcada por uma escrita que aproxima, de forma transgressora, religião e homoerotismo. Essa característica faz parte de um projeto literário do autor que, no prefácio de Bundo, deixa evidente a intenção de aproximar o sagrado do erótico:

Há um desenvolvimento gradativo do tema axial, que é Deus [...] Tal dinâmica não foi premeditada, tornou-se imperativa enquanto elaborava os poemas em momentos regidos por marés secretas. Sempre reconsiderei certos aspectos de minha cosmovisão homoerótica e certas percepções dos significados do corpo-templo e seus membros vibráteis, cheios da presença de Deus [...] (MOTTA, 1996, p. 8).

3 Atualmente, o autor grafa o próprio nome com inicial "W" ao invés de "V" por questões numerológicas; no entanto, optamos por nos referir ao nome dele conforme está grafado na obra em discussão. 
Pelo fragmento, fica claro que um dos temas principais dos poemas do autor é Deus, em suas mais variadas manifestações. Se o corpo é templo do Espírito Santo, a poesia de Valdo Motta vai explorá-lo como manifestação do sagrado, fazendo referência ao baixo corporal, o que possivelmente causa estranhamento ao leitor, ao entrar em contato com sua obra, como o poeta admite em depoimento divulgado por Vieira Jr. (2010, p. 1):

Sempre fui considerado um poeta indecente, obsceno. Isto porque eu sempre misturei baixo calão com alto calão. O mais chocante de tudo é que [...] quanto mais eu procuro Deus, o sagrado, eu sempre acabo chegando aos 'países baixos', a uma geografia muito interessante do corpo humano. [...] Desde o início da história humana, existem tabus. E o que eu descobri nas minhas pesquisas e que reflete na minha poesia, é que a sexualidade é tanto a perdição quanto a salvação da humanidade (grifo do autor).

Por essas afirmações, já podemos perceber que a poesia de Bundo (1996) irá construir uma ligação entre polos aparentemente opostos. O termo principal do título do livro, segundo Simon (1998, p. 173), "significa indivíduo do povo africano Bundo, língua de negro, língua errada, maneira errada de falar e ser, coisa ruim, coisa ordinária" ou ainda seria, como o poeta afirma, o marido da bunda. É nessa linha de entrelaçamento do profano e do 
sagrado que os poemas estabelecem relação dialógica com a Bíblia, à medida que retomam figuras e imagens dos textos bíblicos: as referências a montes sagrados, Deus, vara, rochedo sempre irão metaforizar partes do corpo.

As nádegas e o ânus são as partes do corpo mais "sacralizadas" nos poemas, o sujeito poético as exalta e as deseja, como lemos no poema "Exortação":

Venerai o Santo Fiofó,/ ó neófito das delícias, / e os deuses hão de vos abrir as portas/ das inúmeras moradas do Senhor/ e a fortuna vos sorrirá/ com todos os encantos e prodígios (MOTTA, 1996, p. 32).

Veja-se, no poema, que o ânus referido como "Santo Fiofó" é grafado com letra maiúscula, demonstrando um respeito pela parte do corpo tida, no texto, como sagrada; o título do poema já remete à sua mensagem: exortar é incentivar, dar estímulo, e os verbos empregados no modo imperativo nos remetem aos discursos religiosos em que o "neófito" - sujeito que acabou de ou vai ser batizado - ouve recomendações de como agir para que as portas das moradas do Senhor sejam abertas. O "neófito das delícias" deve, portanto, venerar o ânus para alcançar os "encantos e prodígios".

O emprego lexical aproxima o poema da linguagem bíblica, o vocativo "ó neófito" e as palavras do verso "e os deuses hão de vos abrir as portas" são facilmente encontradas em versículos bíblicos. A forma verbal 'hão', o 
pronome pessoal oblíquo 'vos' nos fazem lembrar a linguagem do discurso dos Salmos, a saber, no Salmo 22:29, lemos "Todos os opulentos da terra hão de comer e adorar [...]", também no Salmo 96:9: “Adorai o Senhor na beleza da sua santidade; tremei diante dele, todas as terras". Veja-se que as formas verbais ("hão", "adorai", "tremei") são semelhantes nos versículos e no poema. A maioria dos textos de Bundo (1996) é construida através dessa linguagem que incorpora estruturas sintáticas usadas na Bíblia: o tom sacro, de respeito e de subserviência, configurado a partir da seleção lexical, das estruturas sintáticas, do emprego de formas verbais comuns nos textos bíblicos.

É recorrente nos poemas a alusão a montes relacionados à bunda:

Ó mãos abençoadas, que sondais/ os montes gêmeos;/ falanges sagradas, que recreais/ na toca da serpente./ Nações do mundo inteiro,/ eis o meu canto:/ é tempo de alegria, de brincar/ no monte santo (MOTTA, 1996, p. 27).

As curvas das nádegas são inscritas no poema como as curvas de montes gêmeos, o sujeito poético define esses montes (que curiosamente são também a "toca da serpente") como santos, sagrados. Na Bíblia, há diversas menções a montes que serviam de local de encontro com Deus, como exemplo se pode mencionar que Moisés recebeu as tábuas da lei no alto do Monte Sinai e Elias obteve o milagre da chuva após ter orado no 
alto do Monte Carmelo, dentre muitas outras referências.

Segundo Chevalier e Gheerbrant (2002), os montes/montanhas, por sua verticalidade, possuem uma simbologia voltada para a ascensão, estabelecendo uma conexão com o alto. No poema em questão, os montes gêmeos que aludem às nádegas parecem ter essa conotação de local sagrado, local de encontro, de conexão com Deus. Devemos apontar que as estratégias recorrentes de alusões ao sagrado para expressão do desejo homoerótico, nos poemas de Valdo Motta, remetem à carnavalização que atualiza visões sob outras perspectivas; observamos que o sagrado, comumente interpretado como sentimento gestado e direcionado para o alto, daí as imagens que se referem a montes (elevação), Deus (no alto), vara (para cima), rochedo (forte, protuberante) são subvertidas, ao passo que a ligação com o homoerótico se dá na posição contrária: com o baixo corporal: as nádegas, o pênis. A carnavalização se dá justamente quando esses símbolos são convertidos de sua relação do alto para o baixo, do espiritual para o corporal.

Essa conotação dos montes como parte do corpo do homem que se conecta ao divino pode ser lida na maioria dos poemas, como em "Encantamento":

Ó Deus serpentecostal que habitais os montes gêmeos e fizeste do meu cu o trono do vosso reino, santo, santo, santo espírito 


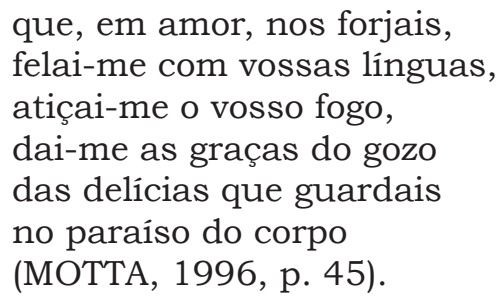

Acreditamos que, nesse poema, podemos perceber alguns aspectos recorrentes nos textos de Valdo Motta: a linguagem subversiva, o emprego de termos que rompem o véu da moralidade e do discurso teológico. O texto é construído como uma oração em que o sujeito poético inicialmente invoca o divino que é adjetivado com o neologismo "serpentecostal" e, ao dissecá-lo, nos deparamos com a visualização de, pelo menos, duas expressões: "ser pentecostal" e "serpente costal". Detendo-nos nesta, o adjetivo "costal" significa dorsal ou das costas, assim, seria uma serpente das costas ou que vive às costas do indivíduo; a serpente na Bíblia é, na maioria das vezes, associada ao pecado e a Satanás, um animal maldito, mas, conforme Chevalier e Gheerbrant (2002), também simboliza a fertilidade e o falo. Dessa maneira, a invocação ao Deus já demonstra uma perspectiva transgressora.

O sujeito poético afirma que Deus habita nos montes gêmeos (alusão às nádegas, como já mencionamos) e fez de seu "cu" o reino dele; como nos demais poemas discutidos, os sujeitos poéticos afirmam que o ânus é a morada do divino. Após a invocação, o sujeito passa a uma petição: pede a Deus que lhe conceda 
prazeres sexuais. A forma verbal no imperativo "felai-me" é um neologismo comum à oralidade e diz respeito à penetração, ao intercurso sexual que o eu poético deseja ter com as línguas do Deus. Dessa forma, o poema se apresenta com uma linguagem que constrói uma dessacralização da figura divina, uma vez que denomina o local sujo ${ }^{4}$, o canal expelidor de excremento do corpo humano, como local sagrado, como morada do que é considerado absolutamente puro, santificado; mais uma vez, vemos a mescla do alto (sagrado) com o baixo corporal (profano), do puro com o impuro, do espírito com a carne.

A configuração, no poema "Encantamento", de Deus como uma serpente ou falo que está às costas do indivíduo, nos remete a outro poema: "Deus atrás de todo mundo./ Deus fiel e bão, que atiça/ o fogo da vida em nosso rabo" (MOTTA, 1996, p. 30). Em ambos os poemas, o sujeito poético deseja a cópula com Deus. Detendo-nos em outra interpretação, o termo "serpentecostal" como 'ser pentecostal' nos remete ao episódio do dia de Pentecostes, narrado no livro de Atos, em que os apóstolos pregaram para pessoas oriundas de diferentes nações que entenderam a mensagem pregada, cada um em sua língua, apesar de os discípulos não dominarem o falar dos outros povos, o que ficou conhecido como o "dom de línguas".

\footnotetext{
4 Empiricamente, denomina-se o ânus de "local sujo", por ser o canal de expulsão das fezes, dejetos do corpo. No entanto, para o homoerotismo masculino, o ânus é de fundamental importância para a realização sexual e assume, de fato, também a função de órgão sexual.
} 
No poema, os versos "felai-me com vossas linguas/ atiçai-me o vosso fogo" (MOTTA, 1996, p. 45) nos lembra a passagem de Atos $2: 3$ e $4:$

E apareceram entre eles, linguas como de fogo, e pousou uma sobre cada um deles. Todos ficaram cheios do Espírito Santo e passaram a falar em outras línguas, segundo o Espírito lhes concedia que falassem.

Observamos que os termos língua, fogo e a palavra felar, como corruptela de falar, aproximam os dois textos. O eu lírico adapta o fogo que desceu sobre os apóstolos no dia de Pentecostes em fogo, como empregado no dizer popular, do tesão sexual, penetrado pelas linguas, remetendo ao ato sexual denominado de cunilíngus, gíria que, segundo Vip e Lib (2007), designa o sexo oral na região do ânus. Ora, se a bunda é o reino, a língua falada nele é estranha (o que nos remete ao universo Pentecostal): línguas de fogo, de felação que permitem a cópula com o divino.

Trevisan (2002), ao discorrer a respeito das práticas do shivaísmo (religião nascida na Índia, em 6000 a.C.) e sua influência sobre a cultura ocidental, afirma que é através da vivência erótica que se chega à raiz do ser humano, e a experiência sexual seria o caminho mais direto para o divino:

Exercitar a sensualidade é, portanto, encontrar-se com Deus através do 
êxtase presente no orgasmo, que permite ao ser humano romper as barreiras do racional e atingir um nivel de profundidade pessoal muito além do pensamento lógico (TREVISAN, 2002, p. 256).

Os poemas de Valdo Motta parecem explicitar esse desejo de contato profundo com o divino, com o sagrado, aproximando, de tal forma, criatura e criador que eles passam a ser apenas um através da cópula anal, haja vista que Deus sempre está atrás dos sujeitos poéticos e habita nos "montes gêmeos [ou no] Santo Fiofó [ou nos] montes rebolantes" (MOTTA, 1996, p. 42).

Passagens bíblicas que estão compiladas no livro de poemas também demonstram essa característica da relação do eu poético com o divino: Em primeiro lugar, de que Deus sempre está à traseira dos indivíduos:

(a) [...] os teus ouvidos ouvirão atrás de ti uma palavra, dizendo: Este é o caminho, andai por ele (Isaías 30: 21);

(b) $[\ldots]$ ouvi por detrás de mim uma voz de grande estrondo, que [...] dizia: Bendita seja a glória do Senhor (Ezequiel 3:12);

(c) Achei-me em espírito, no dia do Senhor, e ouvi, por detrás de mim, grande voz, como de trombeta (Apocalipse 1:10).

É interessante observarmos que, nessas três passagens de livros proféticos, a voz do 
Senhor fala aos profetas sempre por trás deles, às costas dos personagens; evidentemente, essa é uma possibilidade interpretativa das narrações de Isaías, Ezequiel e João, entretanto, a postura divina nos poemas de Valdo Motta, que discutimos brevemente, parece ter um respaldo nas experiências dos profetas.

Em segundo lugar, Deus habita no centro, no mais íntimo de cada individuo:

(d) $[\ldots]$ o Senhor, teu Deus, está no meio de ti (Deuteronômio 7:21);

(e) [...] tu, ó Senhor, estás no meio deste povo [...] (Números 14:14);

(f) $[\ldots]$ o reino de Deus está dentro de vós (Lucas 17:21).

Nessas passagens, fica claro que a presença de Deus se faz no íntimo do ser humano, no meio do povo. Nos poemas discutidos, o centro é configurado como o ânus, o meio do corpo. Lembremos que essa parte do corpo é metaforizada como montes santos, 1ocais que remetem ao encontro com o divino, na Bíblia.

Além disso, nas culturas xamânicas e hindu, conforme Chevalier e Gheerbrant (2002), o homem possui chakras que são pontos ocultos no corpo humano por onde circulam a energia vital e flui a comunicação com o divino. O mais importante desses pontos, para essas religiões, é o chakra de base, responsável pela sobrevivência e poder pessoal, localizado na região do períneo, e nos reme- 
te à localização corporal de manifestação do sagrado nos poemas de Valdo Motta, isto é, a região anal.

Ainda podemos argumentar que os poemas ora comentados constroem o que Bakhtin denominou de carnavalização e, conforme Morson e Emerson (2008), caracteriza-se pela inversão de valores, pela subversão, por uma atitude de dessacralização. Uma das estratégias da carnavalização no texto literário é a referência ao baixo-corporal, empregando uma linguagem que rompe com padrões morais e religiosos. Em Bundo (1996), podemos visualizar a carnavalização da visão cristã sobre a religião, sobre o divino e a sexualidade. Os poemas conseguem subverter esses conceitos, quando estabelecem relação dialógica com o texto bíblico, lançando mão de novas significações para estes. Com efeito, a alusão à cópula com o divino, a conversão dos montes santos nas nádegas masculinas dessacralizam a perspectiva cristã a respeito da relação entre o corpo e a religião; se, no versículo de I Corintios 6:19, o corpo é templo abstrato do Espírito Santo, nos poemas de Valdo, tornase "templo" concreto onde Deus pode entrar e provocar prazeres inefáveis. 


\section{REFERÊNCIAS}

BARCELLOS, José Carlos. Literatura e homoerotismo em questão. Rio de Janeiro: Dialogarts, 2006.

BERGAÇO, Ériton. B. Bundo, o erotismo sagrado da bunda: a construção poética de Waldo Motta em Bundo e outros poemas. In: LOPES, Denílson et al. (Org.) Imagem e diversidade sexual - estudos da homocultura. São Paulo: Nojosa Edições, 2004.

BÍBLIA. Português. Bíblia Sagrada: Antigo e Novo Testamento. Tradução de João Ferreira de Almeida. 2. ed. rev. e atual. Barueri: Sociedade Bíblica do Brasil, 1993.

CHEVALIER, Jean; GHEEBRANT, Alain. Dicionário de simbolos: (mitos, sonhos, costumes, gestos, formas, figures, cores, números). Tradução de Vera da Costa e Silva et al. 17. ed. Rio de Janeiro: José Olympio, 2002.

FIORIN, José Luiz. Introdução ao pensamento de Bakhtin. São Paulo: Ática, 2006.

FRY, Peter; MACRAE, Edward. O que é homossexualidade? 2. ed. São Paulo: Brasiliense, 1983.

HALL, Stuart. A identidade cultural na pósmodernidade. Tradução de Tomaz Tadeu da Silva; Guacira Lopes Louro. Rio de Janeiro: DP\&A, 1997. 
LUGARINHO, Mário César. Literatura de Sodoma: o canône literário e a identidade homossexual. Revista Gragoatá, Niterói, v. 14, p. 133-147, $1^{\circ}$ sem. 2003.

. Nasce a literatura gay no Brasil: reflexões para Luís Capucho. In: SILVA, Antonio de Pádua Dias da (Org.). Aspectos da literatura gay. João Pessoa: Editora Universitária da UFPB, 2008.

MAGALHÃES, Antonio Carlos de Melo; SILVA, Eli Brandão da. Religião, sexualidade e representação de gênero: considerações introdutórias. In: SILVA, Antonio de Pádua Dias da (Org.). Identidades de gênero e práticas discursivas. Campina Grande: Editora Universitária; UEPB, 2008.

MORSON, Gary Saul; EMERSON, Caryl. Mikhail Bakhtin: criação de uma prosaística. Trad. Antonio de Pádua Danesi. São Paulo: EdUSP, 2008.

MOTTA, Valdo. Bundo e outros poemas. Campinas: Editora da UNICAMP, 1996.

SILVA, Antonio de Pádua Dias da. Considerações sobre uma literatura gay. In: SILVA, P. D. da; ALMEIDA, M. L. L.; ARANHA, S. D. G. (Org.). Literatura e linguistica - teoria, análise e prática. João Pessoa: Editora Universitária da UFPB, 2007. 
SILVA, Eli Brandão da. O símbolo na metáfora : fronteira entre o literário e o teológico. In. SILVA, Antonio de Pádua Dias da (Org.) Literatura e estudos culturais. João Pessoa: Editora Universitária da UFPB, 2004.

SIMON, Iumna Maria. Sobre a poesia de Valdo Motta. revistausp, São Paulo, v. 36, p. 172177, dez.-jan.-fev. 1997-1998. (Entrevista).

TREVISAN, João Silvério. As formas bizarras do sagrado. In: _. Pedaço de mim. Rio de Janeiro: Record, 2002.

VIEIRA JR, Erly. A desbundada poesia erótico-mistica de Waldo Motta. [S.1.; [21--]]. Disponivel em: <http: / /www.overmundo.com.br/ overblog/a-desbundada-poesia-erotico-mistica-de-waldo-motta>. Acesso em: 26 jul. 2010.

VIP, Angelo; LIBI, Fred. Aurélia, a dicionária da lingua afiada. São Paulo: Editora da Bispa, 2007. 